\title{
Efficacy of Bacterial Photodynamic Inactivation with varying Angle and Time of LED Exposure
}

\author{
Suryani D. Astuti ${ }^{1, \mathrm{a}, \mathrm{b}}$, Winda P. Lestari ${ }^{2, \mathrm{a}}$, Deny Arifianto ${ }^{3, \mathrm{~b}}$ \\ Anggraini Pertiwi ${ }^{4, b}$ \\ ${ }^{\mathrm{a} D e p a r t m e n t ~ o f ~ P h y s i c s ~ F a c u l t y ~ o f ~ S c i e n c e s ~ a n d ~ T e c h n o l o g y ~}$ \\ Airlangga University, Surabaya, Indonesia

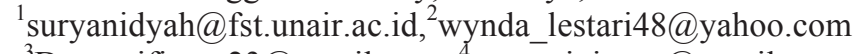 \\ 32Denyarifianto23@gmail.com, ${ }^{4}$ anggrainiprtw@gmail.com
}

\author{
Irawan P. Buditomo ${ }^{5, \mathrm{~b}}$, Nike D.G. Drantantiyas ${ }^{6, \mathrm{a}}$, Ernie M. \\ Setiawatie ,c $^{7}$ \\ ${ }^{\mathrm{b}}$ Post graduate Program in Biomedical Engineering \\ ${ }^{\mathrm{c}}$ Faculty of Dentistry \\ Airlangga University, Surabaya, Indonesia \\ 5aksoro_jowo@yahoo.co.id, ${ }^{6}$ grevika@gmail.com, \\ 7ernie-m-s@fkg.unair.ac.id
}

\begin{abstract}
Streptococcus mutans (S. mutans) is a bacterium that plays a major role in the occurrence of dental caries. Dental caries is a disease that destroys tooth structure, consequently the tooth becomes perforated as well as the sustainable state of accumulation of $S$. mutans excess in the oral cavity can cause damage to the tooth nerve. One alternative treatment of caries is Photodynamic Inactivation (PDI). PDI is a method of microbial inactivation using light and photosensitizer (PS). The absorption of light energy by PS molecules can produce reactive oxygen species that will damage the bacterial cells. Clinical antimicrobial photodynamic therapy using a light source is generally performed at various angles of irradiation depending on the position of the tooth. The amis of this study is to analyze the effect of LED lamination angle $(450.00 \pm 0.21) \mathrm{nm}$ for inactivation of S. mutans by adding PS chlorophylls of Moringa oliefera leaf with concentration $8 \mathrm{mg} / \mathrm{ml}$. Total Plate Count (TPC) was used to determine the decreasement of bacterial viability in CFU / $\mathrm{ml}$. The ANOVA test showed that the irradiation with variation of $90^{\circ}$ exposure angle and $180 \mathrm{~s}$ exposure time potentially inactivated was significantly different with other treatment variation $(\mathrm{p}<\alpha=0,05)$. The $90^{\circ}$ LED illumination angle with $180 \mathrm{~s}$ LED time exposure to produce percentage decrease of bacterial colony $(30.30 \pm$ $4.23) \%$ without PS chlorophyll and (46.74 \pm 1.67$) \%$ with PS chlorophyll. So the angle and duration of exposure time of LED influence PDI efficacy.
\end{abstract}

\section{Keywords-angle exposure, PDI, LED, chlorophyll}

\section{INTRODUCTION}

Dental caries is a disease that destroys tooth structure consequently the tooth becomes hollow. This caused by the excessive accumulation of normal bacteria Streptococcus mutans ( $S$. mutans) that interact with saliva, as well as the parts that come from food in the oral cavity. If this condition does not get immediate treatment will damage the tissue deeper until the pulp place attached to the tooth nerve [1].

Systemic treatment with antibiotics causes resistance of $S$. mutans to certain types of antibiotics for a long time [2]. So it is necessary to look for alternative methods, one of which is with Photodynamic Inactivation (PDI)[3]. PDI is an in vitro approach to inactivation of microorganisms [4]. The combination of light and certain photosensitizer in PDI will cause photoinactivation in bacteria [5].

The use of photodynamic methods both in clinical and in vitro has been widely investigated. The results of the study [6] [7] [8] show that PDI can decrease the number of bacteria and biofilms resistant to antibiotics. Antimicrobial effects of toluidine blue $\mathrm{O}$ (TBO) and a low-energy light emitting diode (LED) after conventional disinfection of $\mathrm{NaOC} 6 \%$ have the potential to be used as additional antimicrobial procedures in conventional endodontic therapy [9].

One of the most widely used light sources in photoinactivation that resides in the photosensitivity absorption spectrum is the Light Emitting Diode (LED). The color of light emitted by the LED depends on the material and condition of the inserted semiconductor, both infrared, visible light, and ultraviolet [10]. The advantages of LEDs, among others, produce heat in small quantities, so it does not cause any photothermal effects. LEDs have been widely used in photodynamic therapy [11].

Photosensitizer (PS) is a light-sensitive substance that plays a role in the absorption of light in PDI. The endogenous PS is produced naturally by bacteria. The absorption of light can be increased by giving exogenous PS. Organic photosensitizers are generally extracted from natural ingredients such as chlorophyll from green plants and photosynthetic bacteria. Chlorophyll has porphyrin-like photophysics properties, with an absorption areas as well as greater intensity of porphyrins [12]. Various PDI studies using LED sources, diode laser and PS chlorophyll have reported successful photoinactivation in microbes [13-15].

The use of LED light sources in clinical antimicrobial photodynamic therapy is generally performed at various angles of irradiation depending on the position of the tooth. This study aims for the effectiveness of antimicrobial photodynamic inactivation at various angles of LED irradiation and exogenous PS chlorophyll Moringa leaf (Moringa oliefera). 